\title{
HER2 expression in cervical cancer as a potential therapeutic target
} Alma Chavez-Blanco ${ }^{1}$, Victor Perez-Sanchez ${ }^{2}$, Aurora Gonzalez-Fierro ${ }^{1}$, Teresa Vela-Chavez ${ }^{2}$, Myrna Candelaria ${ }^{3}$, Lucely Cetina ${ }^{3}$, Silvia Vidal ${ }^{1}$ and Alfonso Dueñas-Gonzalez*1

\begin{abstract}
Address: ${ }^{1}$ Unidad de Investigación Biomédica en Cáncer. Instituto Nacional de Cancerología-Instituto de Investigaciones Biomédicas, UNAM, Av. San Fernando No. 22, Tlalpan 14080, Mexico City, ${ }^{2}$ Department of Pathology, Instituto Nacional de Cancerología; Av. San Fernando No. 22, Tlalpan 14080, Mexico City and ${ }^{3}$ Division of Clinical Research, Instituto Nacional de Cancerología. Av. San Fernando No. 22, Tlalpan 14080, Mexico City

Email: Alma Chavez-Blanco - celular_alma@hotmail.com; Victor Perez-Sanchez - pesv2003@yahoo.com.mx; Aurora GonzalezFierro - aufierro@hotmail.com; Teresa Vela-Chavez - velat@yahoo.com.mx; Myrna Candelaria - mcandelaria@incan.edu.mx; Lucely Cetina - micuentalucely@yahoo.com; Silvia Vidal - vidalms@avantel.net; Alfonso Dueñas-Gonzalez* - alduenas@Prodigy.Net.mx

* Corresponding author
\end{abstract}

Published: 0 I September 2004

BMC Cancer 2004, 4:59 doi:10.1 I86/147|-2407-4-59
Received: 14 April 2004

Accepted: 0I September 2004

This article is available from: http://www.biomedcentral.com/I47I-2407/4/59

(c) 2004 Chavez-Blanco et al; licensee BioMed Central Ltd.

This is an open-access article distributed under the terms of the Creative Commons Attribution License (http://creativecommons.org/licenses/by/2.0), which permits unrestricted use, distribution, and reproduction in any medium, provided the original work is properly cited.

\begin{abstract}
Background: Trastuzumab, a humanized monoclonal antibody against the HER2 receptor is currently being used in breast and other tumor types. Early studies have shown that a variable proportion of cervical carcinoma tumors overexpress the HER2 receptor as evaluated by diverse techniques and antibodies. Currently it is known that a tumor response to trastuzumab strongly correlates with the level of HER2 expression evaluated by the Hercep Test, thus, it seems desirable to evaluate the status of expression of this receptor using the FDA-approved Hercep Test and grading system to gain insight in the feasibility of using trastuzumab in cervical cancer patients.

Methods: We analyzed a series of cervical cancer cell lines, the primary tumors of 35 cases of cervical cancer patients and four recurrent cases, with the Hercep Test in order to establish whether this tumor type overexpress HER2 at level of $2+/ 3+$ as trastuzumab is currently approved for breast cancer having such level of expression.

Results: The results indicate that only I out of 35 primary tumors cases overexpress the receptor at this level, however, two out of four recurrent tumors that tested negative at diagnosis shifted to Hercep Test 2+ and 3+ respectively.

Conclusions: The low frequency of expression in primary cases suggests that trastuzumab could have a limited value for the primary management of cervical cancer patients, however, the finding of "conversion" to Hercep Test $2+$ and $3+$ of recurrent tumors indicates the need to further evaluate the expression of HER2 in the metastatic and recurrent cases.
\end{abstract}

\section{Background}

Cervical carcinoma is a leading cause of death in women of reproductive age worldwide, particularly in developing countries. While curable in early stages, the treatment results of locally advanced disease are unsatisfactory. The current standard of treatment -cisplatin-based chemoradiation- fails to cure at least $15 \%$ to $45 \%$ of bulky IB to IIIB patients, and in addition, multimodality treatment 
incorporating chemotherapy, surgery and radiation at its best is unlikely to substantially increase the cure rate. Because of this, the logical step to follow is the testing of molecular targeted therapies trying to improve the prognosis of cervical cancer patients [1].

Human papillomavirus infection is recognized as the stronger etiological factor for the development of this tumor; however, overexpression of the epidermal growth factor receptor family members is also common and seems to play an important oncogenic role [2]. HER2 (also known as c-erbB-2) is a transmembrane receptor protein with tyrosine kinase activity that belongs to this family and it is overexpressed in a number of solid tumors. Its overexpression and prognostic significance in breast cancer led to the development and approval of the use of trastuzumab (Trastuzumab, Genentech, South San Francisco, CA), a recombinant monoclonal antibody to HER2, for the treatment of patients with metastatic breast carcinomas overexpressing HER2 [3].

Until more recently, poor standardization in HER2 status evaluation precluded reliable comparison of overexpression rates in different tumors. A source of variability in results not only comes from methodological variations in tissue processing (time to fixation, duration of fixation, denaturation, heating, antigen retrieval, the staining procedure) and grading scores but also from the antibody used. This issue was addressed by Press et al., who showed extremely variable results in 187 breast cancer specimens evaluated with 7 polyclonal and 21 monoclonal antibodies [4]. However, standardized methodologies have been introduced recently for these analyses, and have identified frequencies of $51 \%, 44 \%, 26 \%$ and $25 \%$ in Wilm's tumor, bladder, pancreatic and breast carcinoma, respectively. Other tumors tested had frequencies below 20\% [5].

Before the introduction of the Hercep Test, it was known that a variable subset of cervical carcinomas ranging from $8 \%$ to $77 \%$ express HER2 as evaluated by diverse methods [6-14] and that in some studies its overexpression has shown to confer a worse prognosis [7-9,13]. Because these results on HER2 expression in cervical cancer were obtained before the standardization required in breast cancer, we wanted to investigate the expression status of HER2 using the Hercep Test in a series of cervical carcinoma cell lines, primary tumors of locally advanced cervical cancer cases and in four recurrent tumors of these patients.

\section{Methods}

\section{Tumor specimens}

Thirty-five paraffin-embedded tumor tissues from patients FIGO staged as IB2 to IIIB, treated with standard radiation concurrent with weekly cisplatin. Diagnosis was made on the basis of routine hematoxilin-eosin examination under light microscopy according to the World Health Organization criteria. Tumor specimens at diagnosis were taken before any treatment was instituted whereas the tumors samples from the four recurrent cases were also taken before patients received any second line therapy.

\section{Cell lines and reagents}

DMEM culture media and Fetal Calf Serum were purchased from Gibco BRL Life Technologies (Grand Island, New York). HeLa, CasKi, SiHa and C33A carcinoma cell lines were obtained from the ATCC. The cell line ViBo established from a Mexican patient with cervical cancer was kindly provided by Dr. Monroy (FES Zaragoza, UNAM, Mexico City). Cells were grown in DMEM supplemented with $10 \% \mathrm{FCS}$ at $37^{\circ} \mathrm{C}$ and $5 \% \mathrm{CO}_{2}$. Cell lines were grown on two-chamber polysterene vessel Falcon ${ }^{\circledR}$ (Becton Dickinson, NJ.) and subsequently formalin-fixed for $24 \mathrm{hrs}$ at room temperature, then rehydrated in graded ethanol. Afterwards immunochemistry was performed as below described.

\section{Hercep test}

Hercep Test was performed following the manufacturer's guidelines of HER2 protein expression as follows. Sections were deparaffinized in xylene and rehydrated through graded ethanols to distilled water. The sections were immersed in Dako Epitope Retrieval Solution (10 $\mathrm{mM}$ citrate buffer, pH6) that had been preheated to $95^{\circ} \mathrm{C}$ in a water bath and then heat-treated at $95^{\circ} \mathrm{C}$ for $40 \mathrm{~min}$. After a 20-minute cooldown period at room temperature, the sections were washed with Dako Wash Buffer, a procedure that followed every subsequent incubation. Endogenous peroxidase was blocked with Dako Blocking Buffer $(0.3 \%$ hydrogen peroxide containing $15 \mathrm{mM}$ sodium azide) for $5 \mathrm{~min}$ at room temperature. The sections were incubated with the primary polyclonal antibody, an affinity-purified rabbit antihuman HER2 antibody supplied in the kit, for $30 \mathrm{~min}$ at room temperature. Bound primary antibody was labeled by incubating the slides with the Dako Visualization reagent (horseradish peroxidaselabeled dextran polymer conjugated to affinity-purified goat antirabbit immunoglobulins in Tris- $\mathrm{HCl}$ ) for $30 \mathrm{~min}$. Color development was achieved with 3,3'-diaminobenzidine (DAB) for $10 \mathrm{~min}$. The sections were counterstained with hematoxylin and eosin. To confirm validation of the staining run, control cell slides, which were provided in the kit and consisted of three pelleted, formalin-fixed, paraffin-embedded human breast cell lines with known HER2 positivity (MDA-231: 0; MDA175: 1+; SK-BR-3: 3+), were also stained simultaneously. In the negative controls, the primary antibody was replaced by normal rabbit serum (Dako Negative Control Reagent) for the HER2 primary antibody. The antibody 
used in Hercep Test did not exhibit cross-reactivity to HER3 and HER4 in western blot analysis.

Following the FDA scoring guidelines for breast carcinomas, only membrane staining intensity and pattern were evaluated using the $0-3+$ scale as illustrated in the Hercep Test kit scoring guidelines ( 0 for no staining at all or membrane staining in less than $10 \%$ of the tumor cells; $1+$ for only partial, weak staining of the cell membrane of more than $10 \%$ of the tumor cells; $2+$ for moderate staining of the complete cell membrane in more than $10 \%$ of the tumor cells; $3+$ for intense staining of the complete membrane in more than $10 \%$ of the tumor cells). The analysis was performed by a pathologist (VP-S) familiarized in the use of Hercep Test for breast cancer patients. In accordance with the Hercep Test kit guide, HER2 overexpression was assessed as negative for scores of 0 or $1+$ and positive for scores of $2+$ and $3+$.

\section{FISH in the four recurrent cases}

Amplification of Her-2/neu was evaluated using the PathVysion DNA Probe Kit (Vysis), which uses a dual-color probe for determining the number of copies of both Her2/neu (orange) and the chromosome 17 centromeres (green). The kit was used following the manufacturer's instructions with a few minor modifications. Slides containing $5 \mu$ thick paraffin-embedded tissue sections of studied cervical tumor cases and a known Her-2/neu amplified breast tumor were placed on a slide warmer overnight at $58^{\circ} \mathrm{C}$, followed by deparaffinization in Xilol, dehydration in 100 ethanol, and drying on a slide warmer at 45 to $50^{\circ} \mathrm{C}$. Slides were then pretreated with $0.2 \mathrm{~N}$ hydrochloric acid for 20 minutes, followed by washes in purified water and immersion in Vysis wash buffer. They were subsequently immersed in Vysis protease solution at $37^{\circ} \mathrm{C}$ for 10 minutes, washed in Vysis wash buffer, and dried on the slide warmer. The slides were then immersed in $10 \%$ buffered formalin at room temperature for 10 minutes, immersed in Vysis wash buffer, and dried on the slide warmer. Sections were denatured by placing the slides in formamide for 5 minutes at $72^{\circ} \mathrm{C}$ followed by dehydration in 70, 85 and then $100 \%$ ethanol. Slides were then dried on a slide warmer, and $10 \mu \mathrm{l}$ of probe was applied. They were then coverslipped, sealed and placed in a prewarmed humid incubation chamber at $37^{\circ} \mathrm{C}$ for 21 hours. This was followed by immersion in prewarmed postwash solution at $72^{\circ} \mathrm{C}$ for 2 minutes. The slides were air-dried, and a 4',6-diamidino-2-phenylindole (DAPI) counterstain was applied.

The scoring system used is described in detail in the manufacturer's instruction. A minimum of 60 nuclei were scored by each of 2 observers using a Zeiss Axioskop-2 fluorescent microscope with V.2 filter. The ratio of Her-2/neu signals (orange) to chromosome 17 centromere signals

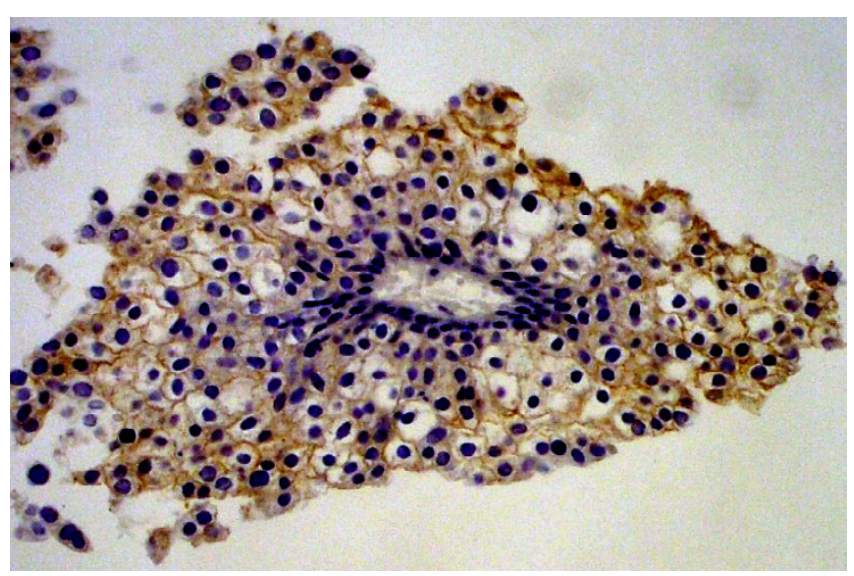

Figure I

Photomicrography of a recurrent tumor positive at a intensity of $2+$. (200X).

(green) was determined with ratios of $<2.0$ considered nonamplified and those $\geq 2.0$ amplified.

\section{Results}

The immunohistochemical expression of HER2 in the primary tumors of 35 patients at diagnosis was evaluated. Accordingly, these patients had no received any previous anticancer therapy; their mean age was 40.8 years; 5 were staged as IB2-IIA, 14 as IIB and 16 as IIIB; 31 and 4 were histologically classified as squamous and adeno/adenosquamous respectively. Overexpression of HER2 was demonstrated in only one out of 35 cases, which had a score of $3+$ (not shown). The remaining cases were interpreted as negative [score of 0]. The case with HER2 overexpression at diagnosis was a 56-year old woman diagnosed with a FIGO stage IIB large cell poorly differentiated squamous cell carcinoma, who received treatment with 6 weekly courses of cisplatin concurrent with external beam radiation and brachytherapy. She is currently free of disease at 44 months of follow-up. At a median follow-up time 40 months, seven patients have relapsed.

HER2 expression at recurrence could only be analyzed in four of these seven relapsed patients in whom whose recurrent disease was histopathologically confirmed. Two of these four tested positive with a staining intensity of $2+$ and 3+ respectively, (Figures 1 and 2), both cases were squamous cell carcinomas and tested negative in the pretreatment surgical specimen

The five cervical cancer cell lines were negative.

None of the four recurrent cases tested by FISH were HER2 amplified (Figure 3). 


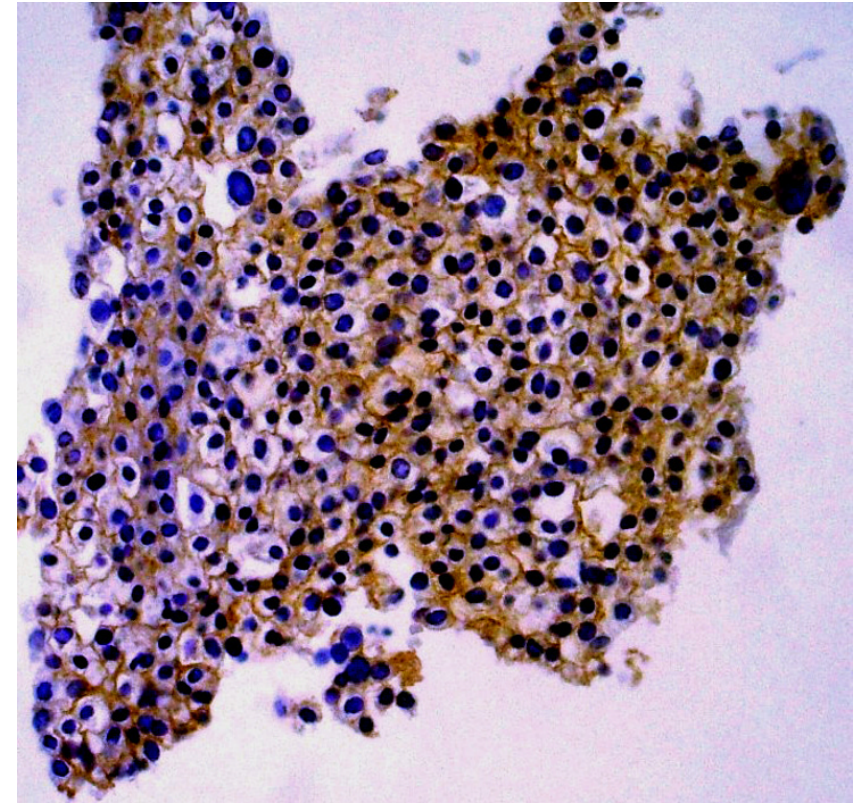

Figure 2

Photomicrography of a recurrent tumor positive at a intensity of $3+$. (200X).

\section{Discussion}

Molecular targeted therapies are currently being tested in a variety of tumor types with promising results. Because HER2 overexpression occurs and is related to a worse prognosis in cervical cancer, [7-9,13], its blockade with trastuzumab could potentially have therapeutic value. This monoclonal antibody is currently widely used in metastatic breast cancer and is being evaluated in an adjuvant setting as well as in a variety of tumor types [3,1517], Based on the fact that the efficacy of this antibody is strongly associated to the level of HER2 expression in the primary tumor, the FDA approved the Hercep Test in the aim to grade the expression level so that only those patients whose tumors exhibit a $2+/ 3+$ levels are candidates to trastuzumab therapy, though currently in most centers, tumors expression of $2+$ is considered undeterminate therefore these cases are also evaluated by FISH analysis [18].

Previous reports on cervical cancer using non-standardized methods for HER2 expression showed that up to $77 \%$ of cases express the receptor and that in general HER2 expression predominates in adenocarcinoma and adenosquamous carcinoma histologies [6-14] In this work, using the Hercep Test with its corresponding guidelines for evaluation, we found contrastating results as none of the cell lines expressed HER2 and only a single tumor of squamous histology (1 out of 35) expresses this oncoprotein at a level of 3+. Such a discrepancy does not seem to be limited to this tumor type. For instances, in ovarian clear cell carcinoma a $43 \%$ of overexpression was reported utilizing systems other than Hercep Test [19], however, when evaluated with this standardized test, only 1 out of 17 tumors expressed $3+[20]$. Likewise, the proportion of patients with $2+/ 3+$ expression level of HER2 with the Hercep Test is uniformly low in tumor such as lung [21], colorectal carcinomas [22], gallbladder [23], and melanoma [24]. A variety of factors such as the kind of antibody used, the technique per se, and scoring criteria may explain such phenomenon and its clarification requires further studies. A recent paper by Bellone et al., have reported that a substantially higher proportion of cervical cancer cells lines either established from fresh tumors or commercial ones (including CasKi, SiHa, HeLa and C33A which are negative by immunochemistry) express the receptor when evaluated by flow-cytometry and are growth inhibited when incubated with trastuzumab or trastuzumab plus IL2 [25]. These data led them to suggest the targeting the HER in cervical cancer could be more effective than the indicated by low immunohistochemical expression [25]. However, it is largely known that in breast [26] and more recently in lung cancer [27], tumor responses are almost confined to those with a $3+$ level of expression. For instances, in a recent published study in 111 assessable breast cancer patients, the response rate to single agent trastuzumab for those expressing $3+$ versus $2+$ was $35 \%$ and $0 \%$ respectively [26], while in lung cancer, a phase II trial of gemcitabine-cisplatin with or without trastuzumab in HER2-positive patients, yet there was not overall differences in response between both arms, the benefit was limited to those with $3+$ of expression with the Hercep Test. Accordingly, five out of six patients with such level of expression receiving trastuzumab plus gemcitabine-cisplatin showed response [27]. These data argue against the potential usefulness of trastuzumab in cervical cancer patients with HER expression that can only be detected by flow cytometry [25].

On the other hand, the HER2 expression in breast cancer is relatively stable, with $95 \%$ concordance between the HER2 status of primary and metastatic lesions, being rare a shift from positivity in the primary to negativity in the metastases [5]. Conversely, 6\% of breast cancer patients whose primary tumors are HER2 negative, convert to high expression (Hercep Test 3+) in their metastases [28]. Such behavior is in line with experimental observations that receptor activation potentiates tumor cell motility, protease secretion and invasion, and also modulates cell cycle checkpoint function, DNA repair, apoptotic responses and multidrug resistance $[29,30]$. The findings of "conversion to positive" in cells of recurrent cervical tumors showed by us and other authors [25,31] strongly suggest that expression of HER2 may have a role in tumor 

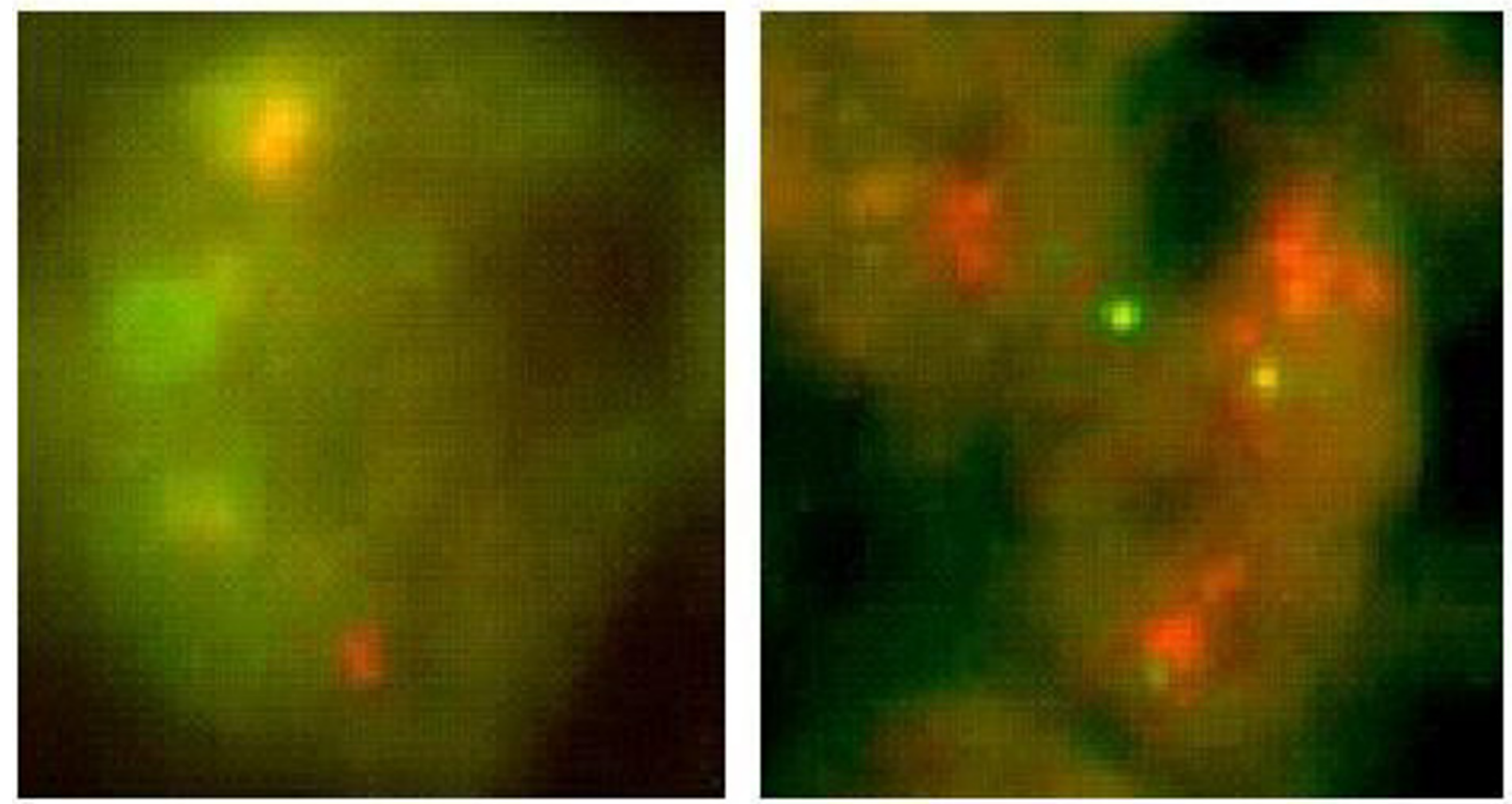

\section{Figure 3}

Photomicrography of the FISH analysis of a negative case of a recurrent tumor that was Hercep Test-positive, and a control positive case of breast carcinoma.

resistance and progression as shown in experimental models, and therefore its targeting in recurrent cervical cancer could have therapeutic value.

It is remarkable the finding that none of the four recurrent cases, including the two that converted to IHC positive analyzed by FISH showed HER2 gene amplification. This result is unlikely to be a false negative as the green signal was perfectly observed in most of the cells. Previous studies in cervical cancer have shown that the frequency of gene amplification as determined by FISH is low irrespective of tumor histology. Mark et al., reported only 2 out of 23 cases amplified using the Her-2/neu FISH probe (Vysis, Inc., Downers Grove, IL) both of which were adenocarcinomas [32]. In a more recent study looking at DNA copy number of cervical adenocarcinomas, it was found that despite more than $50 \%$ of patients had chromosome $17 \mathrm{q}$ copy number gains, only $9 \%$ ( 2 out of 22 ) of these tumors showed an HER-2/neu protein over-expression at the level of $2+$ with the Hercep test. These findings suggest that amplification of HER-2/neu is rare in cervical adenocarcinomas and that low level chromosome 17q copy number gains are not associated with HER-2/neu overexpression [33]. Such overexpression without gene amplification could result from transcriptional deregulation leading to increased receptor expression [34] and is not a rare phenomenon in breast carcinoma [35].

\section{Conclusions}

In conclusion, our study suggest that the clinical usefulness of anti-HER2 antibodies in the primary treatment of cervical cancer patients may be limited due to the low frequency of HER overexpression, nevertheless, it is desirable to further test a larger number of recurrent cervical cancer patients by IHC and FISH analyses regardless of the histological type, as a start point for clinical trials design using trastuzumab.

\section{Competing interests}

None declared.

\section{Authors'contributions}

A C-B, AG-F, carried out the tissue culture work and immunohistochemical analysis; VP-S and T V-C interpreted the histological data; $\mathrm{MC}$ critically analyzed and participated in manuscript; $\mathrm{CP}$, contribute with the clinical data; SV performed the FISH analysis; and AD-G conceived the study and wrote the manuscript. All authors read and approved the final manuscript. 


\section{Acknowledgements}

We thank to Virginia Enriquez for her technical support.

\section{References}

I. Dueñas-Gonzalez A, Cetina L, Mariscal I, de la Garza J: Modern management of locally advanced cervical carcinoma. Cancer Treat Rev 2003, 29:389-399.

2. Chang JL, Tsao YP, Liu DW, Han CP, Lee WH, Chen SL: The expression of type I growth factor receptors in the squamous neoplastic changes of uterine cervix. Gynecol Oncol 1999, 73:62-7I.

3. Horton J: Trastuzumab use in breast cancer: clinical issues. Cancer Control 2002, 9:499-507.

4. Press MF, Hung G, Godolphin W, Slamon DJ: Sensitivity of HER-2/ neu antibodies in archival tissue samples: potential source of error in immunohistochemical studies of oncogene expression. Cancer Res 1994, 54:2771-2777.

5. Menard S, Casalini P, Campiglio M, Pupa S, Agresti R, Tagliabue E: HER2 overexpression in various tumor types, focussing on its relationship to the development of invasive breast cancer. Ann Oncol 200I, I2(SuppI I):SI5-19.

6. Kristensen GB, Holm R, Abeler VM, Trope CG: Evaluation of the prognostic significance of cathepsin $D$, epidermal growth factor receptor, and c-erbB-2 in early cervical squamous cell carcinoma. An immunohistochemical study. Cancer 1996, 78:433-440

7. Oka K, Nakano T, Arai T: c-erbB-2 Oncoprotein expression is associated with poor prognosis in squamous cell carcinoma of the cervix. Cancer 1994, 73:664-671.

8. Kihana T, Tsuda H, Teshima S, Nomoto K, Tsugane S, Sonoda T, Matsuura S, Hirohashi S: Prognostic significance of the overexpression of c-erbB-2 protein in adenocarcinoma of the uterine cervix. Cancer 1994, 73: |48-153.

9. Niibe Y, Nakano T, Ohno T, Suzuki Y, Oka K, Tsujii H: Prognostic significance of c-erbB-2/HER2 expression in advanced uterine cervical carcinoma with para-aortic lymph node metastasis treated with radiation therapy. Int J Gynecol Cancer 2003, I 3:849-855.

10. Lee JS, Kim HS, Jung J, Lee MC, Park CS: Expression of vascular endothelial growth factor in adenocarcinomas of the uterine cervix and its relation to angiogenesis and p53 and c-erbB-2 protein expression. Gynecol Oncol 2002, 85:469-475.

II. Leung TW, Cheung AN, Cheng DK, Wong LC, Ngan HY: Expressions of c-erbB-2, epidermal growth factor receptor and panras proto-oncogenes in adenocarcinoma of the cervix: correlation with clinical prognosis. Oncol Rep 200 I, 8: I I 59-I I64.

12. Hove MG, Dinh TV, Hannigan EV, Lucci JA 3rd, Chopra V, Smith ER, To T: Oncogene expression and microvessel count in recurrent and nonrecurrent stage lb squamous cell carcinoma of the cervix. J Reprod Med 1999, 44:493-496.

13. Nishioka T, West CM, Gupta N, Wilks DP, Hendry JH, Davidson SE, Hunter RD: Prognostic significance of c-erbB-2 protein expression in carcinoma of the cervix treated with radiotherapy. I Cancer Res Clin Oncol 1999, I 25:96-100.

14. Kersemaekers AM, Fleuren G], Kenter GG, Van den Broek LJ, Uljee SM, Hermans J, Van de Vijver MJ: Oncogene alterations in carcinomas of the uterine cervix: overexpression of the epidermal growth factor receptor is associated with poor prognosis. Clin Cancer Res 1999, 5:577-586.

15. Scholl S, Beuzeboc P, Pouillart P: Targeting HER2 in other tumor types. Ann Oncol 200I, I 2(Suppl I):S8I-87.

16. Bookman MA, Darcy KM, Clarke-Pearson D, Boothby RA, Horowitz IR: Evaluation of monoclonal humanized anti-HER2 antibody, trastuzumab, in patients with recurrent or refractory ovarian or primary peritoneal carcinoma with overexpression of HER2: a phase II trial of the Gynecologic Oncology Group. J Clin Oncol 2003, 2 I:283-290.

17. Haddad R, Colevas AD, Krane JF, Cooper D, Glisson B, Amrein PC, Weeks $L$, Costello $R$, Posner $M$ : Herceptin in patients with advanced or metastatic salivary gland carcinomas. A phase II study. Oral Oncol 2003, 39:724-727.

18. Yaziji H, Goldstein LC, Barry TS, Werling R, Hwang H, Ellis GK, Gralow JR, Livingston RB, Gown AM: HER-2 testing in breast cancer using parallel tissue-based methods. JAMA 2004, 291:1972-1977.
19. Fujimura M, Katsumata N, Tsuda H, Uchi N, Miyazaki S, Hidaka T, Sakai M, Saito S: HER2 Is Frequently Over-expressed in Ovarian Clear Cell Adenocarcinoma: Possible Novel Treatment Modality Using Recombinant Monoclonal Antibody against HER2, Trastuzumab. Jpn J Cancer Res 2002, 93:I250-1257.

20. Iwamoto H, Fukasawa H, Honda T, Hirata S, Hoshi K: HER2 expression in ovarian clear cell carcinomas. Int J Gynecol Cancer 2003. 13:28-31.

21. Hirsch FR, Varella-Garcia M, Franklin WA, Veve R, Chen L, Helfrich $B$, Zeng C, Baron A, Bunn PA Jr: Evaluation of HER2 gene amplification and protein expression in non-small cell lung carcinomas. Br J Cancer 2002, 86: | 449-| 456.

22. Nathanson DR, Culliford AT 4th, Shia J, Chen B, D'Alessio M, Zeng ZS, Nash GM, Gerald W, Barany F, Paty PB: HER 2/neu expression and gene amplification in colon cancer. Int J Cancer 2003, I 05:796-802

23. Matsuyama S, Kitajima Y, Sumi K, Mori D, Satoh T, Miyazaki K: Gallbladder cancers rarely overexpress HER2, demonstrated by Hercep Test. Oncol Rep 2004, I I:8I 5-819.

24. Potti A, Hille R, Koch M: Immunohistochemical determination of HER2 in malignant melanoma. Anticancer Res 2003, 23(5A):4067-4069.

25. Bellone S, Palmieri M, Gokden M, Joshua J, Roman J, Pecorelli S, Cannon MJ, Santin AD: Selection of HER2-positive tumor cells in early stage cervical cancer: implications for Trastuzumabmediated therapy. Gynecol Oncol 2003, 91:23 I-240.

26. Vogel CL, Cobleigh MA, Tripathy D, Gutheil JC, Harris LN, Fehrenbacher L, Slamon DJ, Murphy M, Novotny WF, Burchmore M, Shak S Stewart SJ, Press M: Efficacy and safety of trastuzumab as a single agent in first-line treatment of HER2-overexpressing metastatic breast cancer. I Clin Oncol 2002, 20:719-726.

27. Gatzemeier U, Groth G, Butts C, Van Zandwijk N, Shepherd F, Ardizzoni A, Barton C, Ghahramani P, Hirsh V: Randomized phase II trial of gemcitabine-cisplatin with or without trastuzumab in HER2-positive non-small-cell lung cancer. Ann Oncol 2004, I 5:19-27.

28. Gancberg D, Di Leo A, Cardoso F, Rouas G, Pedrocchi M, Paesmans M, Verhest A, Bernard-Marty C, Piccart MJ, Larsimont D: Comparison of HER-2 status between primary breast cancer and corresponding distant metastatic sites. Ann Oncol 2002 , I 3:1036-1043.

29. Eccles SA: The role of c-erbB-2/HER2/neu in breast cancer progression and metastasis. J Mammary Gland Biol Neoplasia 200 I, 6:393-406.

30. Knuefermann C, Lu Y, Liu B, Jin W, Liang K, Wu L, Schmidt M, Mills GB, Mendelsohn J, Fan Z: HER2/PI-3K/Akt activation leads to a multidrug resistance in human breast adenocarcinoma cells. Oncogene 2003, 22:3205-3212.

31. Berchuck A, Rodriguez G, Kamel A, Soper JT, Clarke-Pearson DL, Bast RC Jr: Expression of epidermal growth factor receptor and HER2 in normal and neoplastic cervix, vulva, and vagina. Obstet Gynecol 1990, 76(3 Pt I):38I-387.

32. Mark HF, Feldman D, Das S, Sun CL, Samy M, Lathrop J: HER-2/neu oncogene amplification in cervical cancer studied by fluorescent in situ hybridization. Genet Test 1999, 3:237-242.

33. Dellas A, Torhorst J, Gaudenz R, Mihatsch MJ, Moch H: DNA copy number changes in cervical adenocarcinoma. Clin Cancer Res 2003, 9:2985-2991.

34. Earp HS, Dawson TL, Li X, Yu H: Heterodimerization and functional interaction between EGF receptor family members: a new signaling paradigm with implications for breast cancer research. Breast Cancer Res Treat 1995, 35:115-32.

35. Hammock L, Lewis M, Phillips C, Cohen C: Strong HER-2/neu protein overexpression by immunohistochemistry often does not predict oncogene amplification by fluorescence in situ hybridization. Hum Pathol 2003, 34:1043-1047.

\section{Pre-publication history}

The pre-publication history for this paper can be accessed here:

http://www.biomedcentral.com/1471-2407/4/59/prepub 